\title{
Characterization of symptoms and edema distribution in premenstrual syndrome
}

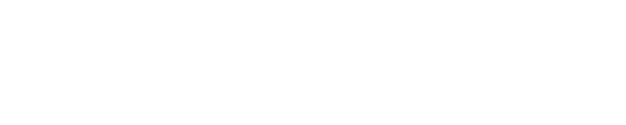

\author{
Pascale Mutti Tacani' \\ Danielle de Oliveira \\ Ribeiro' \\ Barbara Evelyn Barros \\ Guimarães' \\ Aline Fernanda Perez \\ Machado ${ }^{2}$ \\ Rogério Eduardo Tacani ${ }^{1,2}$ \\ 'Physical Therapy Department, São \\ Camilo University Center, ${ }^{2}$ Physical \\ Therapy Department, São Paulo City \\ University (UNICID), São Paulo, Brazil
}

Correspondence: Pascale Mutti Tacani Physical Therapy Department, São Camilo University Center, I50I Nazaré Avenue, Ipiranga, São Paulo 04263-200, Brazil Tel +55 II 03000178585 Email pascale.tacani@hotmail.com
Background: Premenstrual syndrome is a group of symptoms linked to the menstrual cycle, and edema is among these symptoms. Physiotherapy is often sought by many patients for the treatment of edema; however, for an adequate prescription of physiotherapeutic procedures, the distribution of edema throughout the body has yet to be characterized.

Objective: To determine the most frequent symptoms and body regions that present with edema in women during the premenstrual period.

Subjects and methods: Sixty women with a mean age of $24.6 \pm 4.7$ years were evaluated during their premenstrual (between days 21 and 28) and menstrual period (between days 1 and 3), and the collected data included body mass, height, biotype (body-fat distribution), face, breast, limb-circumference measurements, and limb-volume estimate, and an adapted version of the Premenstrual Symptoms Screening Tool was used. Statistical analysis was performed using Student's $t$-test and the test for equality of two proportions $(P \leq 0.05)$.

Results: Premenstrual syndrome was identified in $91.7 \%$ of the women, and the most frequent symptoms were irritability (73.33\%) and physical symptoms, including swelling (65\%), and anxiety (58.3\%). Edema was detected in the following areas: facial, epigastric, mammary, umbilical, and pubic, the mid-third of the arms, distal forearm, in both thighs and in the mid-third of the legs determined by circumference measurements, and in both upper and lower limbs, according to the estimated volume.

Conclusion: In this study population, the most frequent symptoms were irritability, physical symptoms, and anxiety, with distribution of edema in the face, breast, abdomen, pubic area, distal upper limb, and proximal lower limb.

Keywords: premenstrual syndrome, menstrual cycle, edema, women's health, affective symptoms, body surface area

\section{Introduction}

Premenstrual syndrome (PMS) refers to the physical, emotional, cognitive, and behavioral changes that often occur between 10 and 14 days prior to menstruation and disappear with the onset of the menstrual bleeding, and can negatively affect women's daily activities. ${ }^{1}$ It is estimated that $70 \%-90 \%$ of women are affected by some type of symptoms. ${ }^{2}$ This prevalence varies in relation to the population studied and the type of assessment tool used: $37.5 \%$ in Arabian women, ${ }^{3} 17.5 \%$ in Japanese women, ${ }^{4} 25.2 \%,{ }^{5}$ $43.3 \%,{ }^{6}$ and $97.2 \%{ }^{7}$ in Brazilian women, and 41\% in American women, ${ }^{8}$ with the lowest incidence, about 10\%-12\%, in Europe, while Asia has the highest percentage, with 98\%. ${ }^{9}$ Some factors may influence PMS, such as age, menstrual cycle characteristics, socioeconomic and educational levels, use of hormonal contraceptives, and lifestyle, including diet, habits, and physical activities. ${ }^{10,11}$ PMS has been considered a syndrome of multifactorial origin, and is related to the increase of inflammatory reactions and 
oxidative stress and an inadequate overproduction of nitric oxide, as well as superactivation of the renin-angiotensinaldosterone system, possibly due to hormone changes. ${ }^{12}$

There are currently a total of 150 known PMS symptoms that can be variable and inconstant. ${ }^{6}$ The most common symptoms include cravings for certain foods, increased hunger, irritability, anxiety, mood swings, tearfulness, depression, anger, confusion, sleep disorder, social withdrawal, tiredness, headache, stomachache, and back pain, ${ }^{13,14}$ which categorize PMS into four types: PMS-A, PMS-C, PMS-D, and PMS-H. A is predominant anxiety, irritability, and nervous tension; $\mathrm{C}$ with headaches, may be accompanied by increased appetite, desire for sweets, fatigue, palpitations, and tremors; and $\mathrm{D}$, if depression is prevalent, and insomnia, tearfulness, forgetfulness, and confusion. ${ }^{5-7,14}$ PMS-H includes water retention, swelling, breast tenderness, bloating, and weight gain, ${ }^{1,10}$ and this is the type most commonly related with edema, which is the main interest of this study.

The percentage of edema during the premenstrual period can reach $92 \%{ }^{6}$ of women, predominantly in the second phase of the cycle, when progesterone is the main hormone that causes sagging in the venous wall and thus impaired drainage and water retention, ${ }^{15}$ and also by acting as an agonist of aldosterone, it induces natriuresis immediately offset by increased renin..$^{6,12,16}$ In this way, weight gain and edema are the most prevalent physical complaints, with a tendency to be generalized, but the scientific basis of their distribution and prevalence is very restricted. ${ }^{17}$ Swelling has been cited in the breasts, abdomen, and extremities, ${ }^{5,15,17}$ but there is a lack of information regarding measurements to show if it is a clinical condition or a discomfort. ${ }^{10}$ Moreover, this symptom can lead women to seek treatment, including physical therapy, which needs to be planned according to the body areas of edema distribution and complaints. ${ }^{15}$ The modalities in physiotherapy practice applied to treating premenstrual edema can vary according to its distribution in the body. If it is more localized in specific areas, it is possible to work with electrotherapy and metabolic exercises, or if the edema is distributed in general, it is possible to use manual lymphatic drainage and aerobic exercises. ${ }^{11,15,18,19}$ In order to improve physiotherapy practice based on evidence, it is necessary to determine the edema-distribution pattern in the face and/or body regions, when clinically detectable, to prescribe more adequate physiotherapeutic treatments for women with PMS. ${ }^{1,6,15}$ Therefore, this study aimed to verify the most frequent symptoms and the areas of the body that present with edema during the premenstrual period.

\section{Subjects and methods}

This clinical, prospective, and observational study was approved by the Research Ethics Committee of the São Camilo University Center, São Paulo, Brazil (104/011). Participants were students from the São Camilo University Center who were asked to participate in this study by two researchers. The purposive sampling technique was used in order to select women according to the inclusion criteria. Those who agreed to participate were asked to sign an informed consent form in accordance with the National Health Council Resolution 196/96. After this, the participants were evaluated on premenstrual periods and on menstrual periods by means of a physical examination and an adapted version of the Premenstrual Symptoms Screening Tool (PSST). ${ }^{20}$

Brazilian women between 20 and 40 years of age who complained about their premenstrual period were included in this study. The exclusion criteria were reports of thyroid disease, amenorrhea for two or more consecutive cycles, irregular menstrual cycle, use of corticosteroids, diets, or aesthetic treatment.

The participants were evaluated in two situations: 1) premenstrual period between days 21 and 28 of the menstrual cycle, and 2) menstrual period between days 1 and 3 of the cycle. Anamneses provided data regarding the participant's personal information and medical history, and the adapted version of the PSST was applied. ${ }^{20,21}$ The following data were obtained by physical examination: body mass $(\mathrm{kg})$ and height $(\mathrm{m})$ using a mechanical scale $\left(\right.$ Welmy ${ }^{\circledR}$, Campinas, Brazil). These variables were used to calculate the body mass index (BMI; $\left.\mathrm{kg} / \mathrm{m}^{2}\right)$. The body-fat distribution was evaluated by inspecting the participant in a standing position, and it was considered as a biotype that was classified as android (abdominal subcutaneous), gynecoid (lower body), or mixed (abdominal subcutaneous and lower body). ${ }^{22}$ Circumference measurements of the face, trunks, and upper and lower limbs were taken with a measuring tape.

The circumference measurements were obtained by measuring nine circumferences of each limb at every $5 \mathrm{~cm}$ for each upper limb with point zero in the cubital fossa (elbow $0 \mathrm{~cm}$ ). The following measures were obtained: arm $(+20 \mathrm{~cm},+15 \mathrm{~cm},+10 \mathrm{~cm},+5 \mathrm{~cm})$, elbow $(0 \mathrm{~cm})$, and forearm $(-5$ $\mathrm{cm},-10 \mathrm{~cm},-15 \mathrm{~cm},-20 \mathrm{~cm})$. The lower limbs were measured at every $7 \mathrm{~cm}$ with point zero in the popliteal fossa $(\mathrm{knee} 0 \mathrm{~cm})$. The measures were: thigh $(+28 \mathrm{~cm},+21 \mathrm{~cm},+14 \mathrm{~cm},+7 \mathrm{~cm})$, knee $(0 \mathrm{~cm})$, and leg $(-7 \mathrm{~cm},-14 \mathrm{~cm},-21 \mathrm{~cm},-28 \mathrm{~cm}){ }^{23}$ In the trunk, five measurements were standardized in the 
mammary (papillary-areola complex), epigastric ( $5 \mathrm{~cm}$ above the top line of the umbilical scar), umbilical (on the umbilical scar), pelvic ( $5 \mathrm{~cm}$ below the bottom line of the umbilical scar), and pubic (on the pubic bone) areas.

For the head and neck, three measures were standardized in cervical ( $7 \mathrm{~cm}$ below the inferior portion of the ear auricle), submandibular (inferior portion of the right ear auricle up to the left, passing the measuring tape around the submandibular area), and facial (inferior portion of the right ear auricle up to the left, passing the measuring tape around the supralabial area) areas. ${ }^{24}$ The estimated volume of upper and lower limbs was calculated using the circumference values of the respective limbs by the disk-model method: $\mathrm{V}=\sum\left(\mathrm{C}^{2} \times \mathrm{h}\right) / 4 \pi$, where $\mathrm{V}=$ volume, $\sum=$ sum of nine disks of each limb, $\mathrm{C}=$ circumference of the disk, $\mathrm{h}=$ distance between the circumferences, and $\pi=3.14159 .^{23}$

The PSST ${ }^{20}$ was used to define the presence or absence of the PMS in the participants, following criteria listed in the Diagnostic and Statistical Manual of Mental Disorders (DSM)-IV. ${ }^{21}$ In the present study, an adapted version was used in order to identify the symptoms of PMS and not to classify in degrees of severity, as originally proposed by this tool. PMS was considered to be present if the participant complained of five or more symptoms as well as the presence of at least one of the symptoms reported in items 1 (depressed mood or dysphoria), 2 (anxiety or tension), 3 (affective lability), and 4 (irritability). The other items are: 5 (decreased interest in usual activities), 6 (concentration difficulties), 7 (marked lack of energy), 8 (marked change in appetite, overeating, or food cravings), 9 (hypersomnia or insomnia), 10 (feeling overwhelmed) and 11 (other physical symptoms, eg, breast tenderness, bloating, swelling). ${ }^{21}$

The calculation of the sample size and power was performed using Minitab, observing a nominal difference (in the range of data) of 1.7 times the $95 \%$ confidence interval, which for the 60 subjects represented a high sample power of $88.2 \%$ (0.882). For statistical analysis, the KolmogorovSmirnov test was used, and the values obtained showed normal distribution.

Student's paired $t$-test was used for comparisons between premenstrual and menstrual evaluation of the following variables: body mass, BMI, circumference measures, and estimated volume. The test for equality of two proportions was used for the analysis of the relative frequency distribution of PMS symptoms. The level of statistical significance was set at $P \leq 0.05$.

\section{Results}

The population studied included 60 women of a gynecoid biotype, ie, with body-fat distribution in lower body, ${ }^{22}$ with a mean age of $24.6 \pm 4.7$ years. The prevalence of PMS was $91.7 \%(n=55)$, considering five or more symptoms and at least one of items $1,2,3$, or 4 .

In relation to symptoms, item 4 (irritability) showed a prevalence of $73.3 \%$, and was considered as the reference when compared to the other symptoms using the test for equality of two proportions, because it was the most prevalent. There was no significant difference between item 4 (irritability) and items 11 (physical symptoms) and 2 (anxiety), as shown in Table 1.

For the body mass and BMI variables, there was no significant difference between the evaluations performed in the premenstrual and menstrual periods (body mass 62.1 \pm 8.1 and $62.0 \pm 7.9 \mathrm{~kg}$, respectively, $P=0.610$; BMI $23.23 \pm 2.79$ and $23.06 \pm 2.61 \mathrm{~kg} / \mathrm{m}^{2}$, respectively, $P=0.318$ ).

For the circumference measures of face, neck and breast, there were significant differences in the facial, mammary, epigastric, umbilical, and pubic areas, demonstrating that these measures had increased during the premenstrual period, as shown in Table 2 .

The measurements of the upper limbs showed a significant increase in most of them. Significant differences were observed in the right arm in seven of the nine measures, except at $+15 \mathrm{~cm}$ (arm) and $0 \mathrm{~cm}$ (elbow). In the left arm, significant differences were demonstrated in six of nine measures, except at $+20 \mathrm{~cm}$ and $+5 \mathrm{~cm}$ (arm), and $-5 \mathrm{~cm}$ and $-10 \mathrm{~cm}$ (forearm), as shown in Table 3 .

For both lower limbs, significant increases were observed in most of the measurements. On the right side, significant

Table I Prevalence of symptoms described by 60 women

\begin{tabular}{llll}
\hline Symptoms & n & $\%$ & P-value \\
\hline I - Mood swings & 32 & $53.3 \%$ & $0.023^{*}$ \\
2 - Anxiety & 35 & $58.3 \%$ & 0.083 \\
3 - Affective lability & 29 & $48.3 \%$ & $0.005^{*}$ \\
4 - Irritability & 44 & $73.3 \%$ & Reference \\
5 - Decreased interest & 30 & $50.0 \%$ & $0.009 *$ \\
6 - Poor concentration & 26 & $43.3 \%$ & $<0.00$ I $^{*}$ \\
7 - Tiredness & 33 & $55.0 \%$ & $0.036^{*}$ \\
8- Change in appetite & 28 & $46.7 \%$ & $0.003^{*}$ \\
9- Sleep disturbance & 16 & $26.7 \%$ & $<0.00$ I $^{*}$ \\
I0 - Loss of control & 13 & $21.7 \%$ & $<0.00$ I* \\
II - Physical symptoms & 39 & $65.0 \%$ & 0.323 \\
\hline
\end{tabular}

Notes: $* P \leq 0.05$ (test for equality of two proportions). "Reference" refers to the reference for statistical analysis: the highest value used for comparison. Symptoms were described according to the adapted version of the Premenstrual Symptoms Screening Tool. ${ }^{20,21}$ 
Table 2 Circumference measures of face, neck, and trunk

\begin{tabular}{lllll}
\hline Circumference & \multicolumn{1}{c}{ Premenstrual } & & \multicolumn{1}{c}{ Menstrual } & P-value \\
\cline { 2 - 2 } \cline { 5 - 5 } & Mean \pm SD & & Mean \pm SD & \\
\hline Facial & $24.94 \pm 1.95$ & & $24.36 \pm 2.11$ & $0.016^{*}$ \\
Submandibular & $25.38 \pm 2.62$ & & $25.50 \pm 2.68$ & 0.116 \\
Cervical & $31.19 \pm 2.13$ & & $31.11 \pm 2.18$ & 0.286 \\
Mammary & $89.12 \pm 9.08$ & & $86.87 \pm 8.88$ & $<0.00 I^{*}$ \\
Epigastric & $74.63 \pm 8.33$ & & $73.52 \pm 8.08$ & $<0.00 I^{*}$ \\
Umbilical & $81.2 \pm 9.02$ & & $79.34 \pm 8.60$ & $<0.00 I^{*}$ \\
Pelvic & $86.52 \pm 7.14$ & & $85.93 \pm 7.38$ & 0.119 \\
Pubic & $89.93 \pm 8.13$ & $88.75 \pm 7.87$ & $0.003^{*}$ \\
\hline
\end{tabular}

Note: $* P \leq 0.05$ (Student's paired $t$-test).

Abbreviation: SD, standard deviation.

differences were found in eight of nine measures, except at $-7 \mathrm{~cm}$ (calf). On the left side, the differences were significant in seven of the nine measures, except at $+15 \mathrm{~cm}$ (thigh) and $0 \mathrm{~cm}$ (knee), as shown in Table 4.

The estimated volume for both upper and lower limbs showed a statistically significant difference, demonstrating an increase in volume during the premenstrual period, as shown in Table 5.

\section{Discussion}

The present study aimed to analyze the most frequent symptoms and edema distribution in women during the premenstrual period. It was possible to verify that $91.7 \%$ had PMS, with the most prevalent symptoms related to irritability, physical symptoms, and anxiety. Moreover, the edema distribution during the premenstrual period was prevalent in the face, breast, abdomen, pubic areas, and distal upper limbs and proximal lower limbs.

The study population had a high prevalence of PMS, and although the sample did not characterize the female population more extensively as in epidemiological studies, ${ }^{5}$ it was representative of women with PMS, contemplating the objective proposed. All of the women who participated in this study were chosen because they had some complaint related to PMS, and it was identified that most of them presented with PMS (91.7\%), although five did not. This corroborates other studies ${ }^{6,7}$ that investigated PMS characteristics and were also carried out in outpatient clinics or in universities, ${ }^{5}$ and identified that a small proportion of women had some complaints related to PMS, but there was not a syndrome, demonstrating the importance of the diagnosis.

The adapted version of the PSST ${ }^{20}$ was chosen because it follows the DSM-IV criteria and is widely used in the literature. ${ }^{5}$ In addition, it proved to be a practical instrument, particularly in the context of physical and psychological symptoms.

In this study, the anthropometric data of patients were comparable to those obtained by Endrikat et al ${ }^{10}$ whose participants had a mean age of 26.1 years, weight of $60.95 \mathrm{~kg}$, and BMI of $22.77 \mathrm{~kg} / \mathrm{m}^{2}$. The authors did not find significant differences in body weight between the premenstrual and menstrual periods. These data showed the presence of PMS in young women in the period between menarche and menopause who had normal BMI. ${ }^{25}$

The most prevalent symptoms in this population were anger or irritability, affecting $73.3 \%$ of women. This result agrees with that found in the literature, where the emotional symptoms were more intense, ${ }^{5-7,15}$ and changes in estrogen and progesterone levels may explain some symptoms, such as the combination of excess estrogen with agitation and irritability. ${ }^{2,10,13}$

Physical symptoms were the second-most frequent, and included breast tenderness, headache, cramps, and edema. This finding corroborates the classification of PMS in

Table 3 Circumference measures of upper limbs

\begin{tabular}{|c|c|c|c|c|c|c|}
\hline \multicolumn{4}{|l|}{ Right side } & \multicolumn{3}{|l|}{ Left side } \\
\hline \multirow[t]{2}{*}{ Circumference } & Premenstrual & Menstrual & $P$-value & Premenstrual & Menstrual & $P$-value \\
\hline & Mean \pm SD & Mean \pm SD & & Mean \pm SD & Mean \pm SD & \\
\hline$+20 \mathrm{~cm}$ & $32.06 \pm 5.23$ & $3 I .4 I \pm 5.28$ & $<0.00 I^{*}$ & $31.51 \pm 5.29$ & $31.29 \pm 5.28$ & 0.111 \\
\hline$+15 \mathrm{~cm}$ & $29.26 \pm 4.78$ & $29.07 \pm 4.83$ & 0.119 & $29.05 \pm 4.90$ & $28.75 \pm 4.79$ & $0.002 *$ \\
\hline$+10 \mathrm{~cm}$ & $27.56 \pm 3.84$ & $27.32 \pm 3.91$ & $0.001 *$ & $27.18 \pm 3.79$ & $26.98 \pm 3.73$ & $0.012 *$ \\
\hline$+5 \mathrm{~cm}$ & $25.73 \pm 2.84$ & $25.45 \pm 2.79$ & $<0.00 I^{*}$ & $25.42 \pm 3.08$ & $25.27 \pm 2.96$ & 0.088 \\
\hline $0 \mathrm{~cm}$ & $24.34 \pm 2.31$ & $24.27 \pm 2.29$ & 0.225 & $24.31 \pm 2.36$ & $24.05 \pm 2.27$ & $0.003 *$ \\
\hline$-5 \mathrm{~cm}$ & $24.49 \pm 2.44$ & $24.21 \pm 2.46$ & $<0.00 I^{*}$ & $23.94 \pm 2.38$ & $23.85 \pm 2.37$ & 0.089 \\
\hline$-10 \mathrm{~cm}$ & $22.98 \pm 2.85$ & $22.67 \pm 2.79$ & $<0.00 I^{*}$ & $22.39 \pm 2.72$ & $22.26 \pm 2.86$ & 0.101 \\
\hline$-15 \mathrm{~cm}$ & $19.30 \pm 2.54$ & $19.11 \pm 2.49$ & $0.024 *$ & $18.69 \pm 2.55$ & $16.28 \pm 1.98$ & $<0.001 *$ \\
\hline$-20 \mathrm{~cm}$ & $16.63 \pm 1.91$ & $16.4 \mid \pm 2.03$ & $0.008^{*}$ & $16.28 \pm 1.98$ & $16.11 \pm 2.02$ & $0.008^{*}$ \\
\hline
\end{tabular}

Note: $* P \leq 0.05$ (Student's paired $t$-test).

Abbreviation: SD, standard deviation. 
Table 4 Circumference measures of lower limbs

\begin{tabular}{|c|c|c|c|c|c|c|}
\hline \multicolumn{4}{|l|}{ Right side } & \multicolumn{3}{|l|}{ Left side } \\
\hline \multirow[t]{2}{*}{ Circumference } & Premenstrual & Menstrual & $P$-value & Premenstrual & Menstrual & $P$-value \\
\hline & Mean \pm SD & Mean \pm SD & & Mean \pm SD & Mean \pm SD & \\
\hline$+28 \mathrm{~cm}$ & $58.24 \pm 7.15$ & $57.01 \pm 6.75$ & $<0.00 I^{*}$ & $57.98 \pm 7.35$ & $57.02 \pm 6.87$ & $<0.00 I^{*}$ \\
\hline$+21 \mathrm{~cm}$ & $53.09 \pm 6.89$ & $52.42 \pm 6.64$ & $<0.00 I^{*}$ & $53.12 \pm 6.91$ & $52.50 \pm 6.70$ & $0.001 *$ \\
\hline$+14 \mathrm{~cm}$ & $46.80 \pm 6.00$ & $46.43 \pm 5.92$ & $<0.00 I^{*}$ & $46.83 \pm 5.77$ & $46.39 \pm 5.75$ & $<0.00 I^{*}$ \\
\hline$+7 \mathrm{~cm}$ & $41.03 \pm 4.43$ & $40.67 \pm 4.36$ & $<0.00 I^{*}$ & $41.03 \pm 4.43$ & $40.67 \pm 4.36$ & $0.002 *$ \\
\hline $0 \mathrm{~cm}$ & $36.23 \pm 3.59$ & $35.93 \pm 3.36$ & $0.031 *$ & $35.75 \pm 4.53$ & $36.08 \pm 3.41$ & 0.440 \\
\hline$-7 \mathrm{~cm}$ & $35.39 \pm 3.72$ & $35.23 \pm 3.79$ & 0.076 & $35.68 \pm 3.81$ & $35.33 \pm 3.76$ & $<0.00 I^{*}$ \\
\hline$-14 \mathrm{~cm}$ & $36.26 \pm 4.11$ & $36.08 \pm 4.13$ & $0.037^{*}$ & $36.22 \pm 3.99$ & $35.93 \pm 4.03$ & $<0.00 I^{*}$ \\
\hline$-21 \mathrm{~cm}$ & $32.00 \pm 4.12$ & $31.64 \pm 4.06$ & $<0.00 I^{*}$ & $32.10 \pm 3.90$ & $31.60 \pm 4.08$ & $<0.00 I^{*}$ \\
\hline$-28 \mathrm{~cm}$ & $25.97 \pm 3.54$ & $25.69 \pm 3.43$ & $0.003 *$ & $25.69 \pm 3.25$ & $25.68 \pm 3.55$ & 0.936 \\
\hline
\end{tabular}

Note: $* P \leq 0.05$ (Student's paired $t$-test).

Abbreviation: SD, standard deviation.

groups, in which emotional symptoms were more prevalent (PMS-A) and the physical symptoms came in second place (PMS-H). ${ }^{6,14}$

In clinical practice, edema is a common complaint in $92 \%$ of women in the second phase of their menstrual cycle, when the main hormone is progesterone..$^{15}$ In this study, $65 \%$ (Table 1) of women complained of physical symptoms, including edema, higher than in other studies that found a $40 \%$ incidence. ${ }^{6-8}$ Episodes of edema during the menstrual period may have different etiologies, such as sodium and water retention, responsible for bloating, and edema in the mammary region and in the upper- and lower-limb extremities. This retention can occur due to an endocrine disorder when there are variations in estrogen and progesterone. ${ }^{12,26}$ Moreover, not only does the action of progesterone cause the venous wall to sag, affecting the return of blood, but it also acts as an agonist for aldosterone, which induces natriuresis, immediately compensated by increased renin-secretion levels. ${ }^{6,12}$ Changes in renin-angiotensin-aldosterone levels also increase progesterone, which is natriuretic. ${ }^{6,7,12}$

Table 5 Values of the estimated volume (disk method) of upper and lower limbs

\begin{tabular}{lllll}
\hline $\begin{array}{l}\text { Estimated } \\
\text { volume }\end{array}$ & & Premenstrual & Menstrual & $P$-value \\
\hline Right upper limb & Mean \pm SD & $2.306 \pm 689$ & $2.248 \pm 684$ & $<0.00 I^{*}$ \\
& Median & 2.285 & $2.15 I$ & \\
Left upper limb & Mean \pm SD & $2.236 \pm 68 \mathrm{I}$ & $2.198 \pm 675$ & $<0.002^{*}$ \\
& Median & 2.178 & $2.1 I I$ & \\
Right lower limb & Mean \pm SD & $8.859 \pm 1.750$ & $8.634 \pm I .673$ & $<0.00 I^{*}$ \\
& Median & 9.360 & 8.896 & \\
Left lower limb & Mean \pm SD & $8.824 \pm I .733$ & $8.647 \pm I .674$ & $<0.00 I^{*}$ \\
& Median & 8.908 & 8.927 & \\
\hline
\end{tabular}

Note: $* P \leq 0.05$ (Student's paired $t$-test). Abbreviation: SD, standard deviation.
Regarding edema distribution, a statistically significant difference was observed in the circumference measures of the facial region, which corroborated the complaints of patients in clinical practice. However, the literature on the subject is insufficient, making comparisons between data with the same population characteristics difficult; however, in studies addressing lymphedema in the head and neck, facial measures were used to evaluate swelling, ${ }^{24,27}$ supporting the methodology used in the present study.

There was swelling all over the trunk, but with a significant difference in the mammary, epigastric, umbilical, and pubic areas. The existence of edema in the breasts may be associated with mastodynia, as during the luteal phase of the menstrual cycle, epithelial cell proliferation is intensified. Estradiol acts in the endothelium to promote vasodilatation, and progesterone increases vascular permeability, facilitating the passage of fluid into the interstitial space and increasing the breast volume. ${ }^{6}$ The volume of the abdominal region (epigastric, umbilical, and pubic) may have increased due to local anatomy, as the uterus becomes widely vascularized during the luteal phase by the action of progesterone, causing greater water retention. ${ }^{15,26}$ The pelvic region may not have been affected by edema, due to the continuous use of modern pants that compress the area and increase drainage. ${ }^{28} \mathrm{Com}-$ pression therapy is one of the main methods used to prevent and treat edema, as it enhances absorption and lymphatic venous flow. ${ }^{28}$

For both upper limbs, there was a variation in the circumference measures for the mid-third of the arm and distal forearm. Edema in the distal regions (forearm and wrist) probably occurs due to water and sodium retention when there is an alteration in the relationship between estrogen and progesterone. ${ }^{10,17,26}$ In addition, fat distribution occurs 
differently in body segments according to biotype, ${ }^{22}$ and in this study population, the women were gynecoid. In this particular biotype, adiposity is predominant in the glutealfemoral regions, causing greater congestion in these microcirculatory areas. ${ }^{22}$ In the upper limbs, there is accumulation of adiposity, which can justify the increasing of the measures on the mid-third of the arm..$^{22,29}$

In the lower limbs, there was a statistically significant difference in the circumference measures of the thigh region and the mid-third of the leg, which can be explained by the gynecoid biotype, as these women had higher amounts of localized adipose tissue and microcirculatory dysfunction in the gluteal-femoral regions associated with the development of cellulite. ${ }^{22,30}$ This pathology begins with water retention increased by cyclical hormonal variations, and one of the main causes of cellulite is hyperestrogenism. This condition induces the accumulation of hyaluronic acid, which increases osmotic pressure, forming edema in the interstitium and reducing the diffusion of nutrients, metabolites, and hormones. ${ }^{30}$ Venous congestion and lymph microcirculation also occurs, causing edema in these regions, ${ }^{29,30}$ as observed in this study sample. Possibly, the last measure of the ankle $(-28 \mathrm{~cm})$ may not have changed significantly because of the use of stockings, which may have acted as compression therapy and prevented the onset of edema..$^{28,29}$

The values obtained from both the upper and lower limbs revealed a significant increase in volume in these body segments, providing an overview of edema behavior. This proved to be relevant in clinical practice, as it demonstrates changes in limb volume, being more representative and understandable to the patient, and also complementary to the circumference measures. ${ }^{23}$

Although edema was detected in most parts of the areas evaluated (facial, epigastric, umbilical, mammary, pubic, thighs, mid-third of the legs and arms, and distal third of the forearm), no significant difference was observed in the variation in body weight and BMI in the premenstrual phase. Possibly, the normal BMI of patients in this study may have contributed to the maintenance of these values, considering that in individuals with normal BMI, there was no significant change in adipocyte morphology (hypertrophy) or in physiology of the dermal and subcutaneous tissue, with respect to the microcirculatory dynamics. ${ }^{22,29,30}$

According to the symptoms and physical changes shown in the population studied, between the premenstrual and menstrual phases, it is possible to improve understanding of the burden for women, especially during the premenstrual period, which can modify psychological and physical conditions for them. These symptoms interfere with daily activities and relationships, demonstrating the need for adequate treatment in order to minimize symptoms and to maintain quality of life for the woman and her social network. ${ }^{1,4,7,31}$

These findings can help health care professionals to decide on the best treatment to control the edema and physical complaints of women with PMS, as there are a lot of resources to treat edema, such as pharmacological ${ }^{1,10,13,16}$ and nonpharmacological agents, ${ }^{16}$ which can include physiotherapeutic modalities (low-level laser therapy, electrotherapy, vacuum therapy as mechanical massage), ${ }^{28,29,31}$ exercises, ${ }^{11,18,26,31}$ compressive therapy, ${ }^{28,29}$ and manual lymphatic drainage. ${ }^{15,29}$ Therefore, more studies are necessary to verify and to compare these therapeutic modalities and their cost-effectiveness.

Edema was evaluated by circumferences and by calculating limb volume, but nowadays better options are available, such as using the tissue dielectric constant, which reflects the content of local tissue water and is sensitive to both free and bound water contained within the volume being measured. ${ }^{32}$ It is used as an index of local tissue water, but at the time of this research we did not have access to this technology, this being one of the limitations of this study. In addition, other factors can influence PMS, such as physical activity, smoking, and alcohol and oral contraceptive use, which were not considered in this sample, demonstrating another limitation of this work.

In conclusion, the most frequent symptoms in this study population were irritability, physical symptoms, and anxiety, with edema distribution in the face, breast, abdomen, pubic areas, and the distal upper and proximal lower limbs. Based on these findings, further studies may be able to investigate other variables, such as different BMI values, types of garments, and occupation. In addition, these results can contribute to prescribing physiotherapeutic measures to meet the needs of patients with PMS and associated edema.

\section{Acknowledgment}

This work was presented at the Second Brazilian Conference of Dermato-Functional Physiotherapy, November 2012, Recife, Brazil.

\section{Disclosure}

The authors report no conflicts of interest in this work.

\section{References}

1. Breech LL, Braverman PK. Safety, efficacy, actions, and patient acceptability of drospirenone/ethinyl estradiol contraceptive pills in the treatment of premenstrual dysphoric disorder. Int J Womens Health. 2009; 1:85-95.

2. Ismail KH, O'Brien S. Premenstrual syndrome. Curr Obstet Gynecol. 2005; 15:25-30. 
3. Rasheed P, Al-Sowielem LS. Prevalence and predictors of premenstrual syndrome among college-aged women in Saudi Arabia. Ann Saudi Med. 2003;23:381-387.

4. Tanaka E, Momoeda M, Osuga Y, et al. Burden of menstrual symptoms in Japanese women: an analysis of medical care-seeking behavior from a survey-based study. Int $J$ Womens Health. 2014;6:11-23.

5. Silva CM, Gigante DP, Carret ML, Fassa AG. [Population study of premenstrual syndrome]. Rev Saude Publica. 2006;40:47-56. Portuguese.

6. Nogueira CW, Silva JLP. [Prevalence of symptoms in premenstrual syndrome]. Rev Bras Ginecol Obstet. 2000;22:347-351. Portuguese.

7. Rodrigues IC, Oliveira E. Prevalência e convivência de mulheres com a síndrome pré-menstrual. Arq Cienc Saude. 2006;13:61-67.

8. Singh BB, Berman BM, Simpson RL, Annechild A. Incidence of premenstrual syndrome and remedy usage: a national probability sample study. Altern Ther Health Med. 1998;4:75-79.

9. Direkvand-Moghadam A, Sayehmiri K, Delpisheh A, Kaikhavandi Sattar. Epidemiology of premenstrual syndrome (PMS) - a systematic review and meta-analysis study. J Clin Diagn Res. 2014;8:106-109.

10. Endrikat J, Sandri M, Gerlinger C, Rubig A, Schmidt W, Fortier M. A Canadian multicentre prospective study on the effects of an oral contraceptive containing $3 \mathrm{mg}$ drospirenone and $30 \mu \mathrm{g}$ ethinyl oestradiol on somatic and psychological symptoms related to water retention and on body weight. Eur J Contracept Reprod Health Care. 2007; 12:220-228

11. Vishnupriya R, Rajarajeswaram P. Effects of aerobic exercise at different intensities in premenstrual syndrome. J Obstet Gynaecol India. 2011;61:675-682.

12. Stamatelopoulos KS, Georgiopoulos G, Papaioannou T, Lambrinoudaki I, Kouzoupis A, Vlachopoulos C. Can premenstrual syndrome affect arterial stiffness or blood pressure? Atherosclerosis. 2012;224:170-176.

13. Sveindóttir H, Bäckström T. Prevalence of menstrual cycle symptom cyclicity and premenstrual dysphoric disorder in a random sample of women using and not using oral contraceptives. Acta Obstret Gynecol Scand. 2012;79:405-413.

14. Abraham GE. Nutritional factors in the etiology of the premenstrual tension syndromes. J Reprod Med. 1983;28:446-464.

15. Ferreira JJ, Machado AF, Tacani R, Saldanha ME, Tacani PM, Liebano RE. [Manual lymphatic drainage for premenstrual syndrome symptoms: a pilot study]. Fisioter Pesq. 2010;17:75-80. Portuguese.

16. Rapkin A. A review of treatment of premenstrual syndrome and premenstrual dysforic disorder. Psychoneuroendocrinology. 2003; 28 Suppl 3:39-53.

17. Rosenfeld R, Livne D, Nevo O, et al. Hormonal and volume dysregulation in women with premenstrual syndrome. Hypertension. 2008; 51:1225-1230.
18. Samadi Z, Taghian F, Valiani M. The effects of 8 weeks of regular aerobic exercise on the symptoms of premenstrual syndrome in nonathlete girls. Iran J Nurs Midwifery Res. 2013;18:14-19.

19. Hernandez-Reif M, Martinez A, Field T, Quintero O, Hart S, Burman I. Premenstrual symptoms are relieved by massage therapy. J Psychosom Obstet Gynaecol. 2000;21:9-15.

20. Steiner M, Macdougall M, Brown E. The premenstrual symptoms screening tool (PSST) for clinicians. Arch Womens Ment Health. 2003; 6:203-209.

21. Steiner M. Premenstrual syndrome and premenstrual dysphoric disorder: guidelines for management. J Psychiatry Neurosci. 2000; 25:459-468.

22. Foster MT, Pagliassotti MJ. Metabolic alterations following visceral fat removal and expansion: beyond anatomic location. Adipocyte. 2012; 1:192-199.

23. Deltombe T, Jamart J, Recloux S, et al. Reliability and limits of agreement of circumferential, water displacement, and optoelectronic volumetry in the measurement of upper limb lymphedema. Lymphology. 2007; 40:26-34.

24. Tacani PM, Santos AP, Poscolere DD, et al. Protocol for assessment of head and neck lymphedema. Rev Bras Cir Cabeca Pescoco. 2010; 39:126-130.

25. World Health Organization. Global Database on Body Mass Index: an interactive surveillance tool for monitoring nutrition transition. Available from: http://www.who.int/bmi/index.jsp?introPage=intro_3. Accessed July 15, 2013.

26. El-Lithy A, El-Mazny A, Sabbour A, El-Deeb A. Effect of aerobic exercise on premenstrual symptoms, haematological and hormonal parameters in young women. J Obstet Gynaecol. 2014:1-4.

27. Smith BG, Lewin J. Lymphedema management in head and neck cancer. Curr Opin Otolaryngol Head Neck Surg. 2010;18:153-158.

28. Partsch H. Compression therapy: clinical and experimental evidence. Ann Vasc Dis. 2012;5:416-422.

29. Tunay VB, Akbayrak T, Bakar Y, Kayihan H, Ergun N. Effects of mechanical massage, manual lymphatic drainage and connective tissue manipulation techniques on fat mass in women with cellulite. $J$ Eur Acad Dermatol Venereol. 2010;24:138-142.

30. Terranova F, Berardesca E, Maibach H. Cellulite: nature and aetiopathogenesis. Int J Cosmet Sci. 2006;28:157-167.

31. Tolossa FW, Bekele ML. Prevalence, impacts and medical managements of premenstrual syndrome among female students: Crosssectional study in College of Health Sciences, Mekelle University, Mekelle, Northern Ethiopia. BMC Womens Health. 2014;14:52.

32. Purcell A, Nixon J, Fleming J, McCann A, Porceddu S. Measuring head and neck lymphoedema: the "ALOHA" trial. Head Neck. Epub 2014 Sep 12.
International Journal of Women's Health

\section{Publish your work in this journal}

The International Journal of Women's Health is an international, peerreviewed open-access journal publishing original research, reports, editorials, reviews and commentaries on all aspects of women's healthcare including gynecology, obstetrics, and breast cancer. The manuscript management system is completely online and includes

\section{Dovepress}

a very quick and fair peer-review system, which is all easy to use. Visit http://www.dovepress.com/testimonials.php to read real quotes from published authors. 